\title{
Correction to: Bioaccumulation of lead in different varieties of wheat plant irrigated with wastewater in remote agricultural regions
}

\author{
Wuyi Liu' ${ }^{1}(1) \cdot$ Asma Zafar $^{2} \cdot$ Zafar Iqbal Khan $^{2} \cdot$ Muhammad Nadeem $^{3} \cdot$ Kafeel Ahmad $^{2} \cdot$ Kinza Wajid $^{2}$. \\ Humayun Bashir ${ }^{2} \cdot$ Mudasra Munir $^{2}$. Ifra Saleem Malik ${ }^{2} \cdot$ Asma Ashfaq $^{2}$
}

Published online: 15 December 2021

○) Springer-Verlag GmbH Germany, part of Springer Nature 2021

Correction to: Environmental Science and Pollution Research (2020) 27:27937-27951

https://doi.org/10.1007/s11356-020-09138-9

In the Abstract line 7, $\mathrm{Cd}$ should be written as $\mathrm{Pb}$.

Publisher's Note Springer Nature remains neutral with regard to jurisdictional claims in published maps and institutional affiliations.

The original article can be found online at https://doi.org/10.1007/ s11356-020-09138-9.

Wuyi Liu

lwycau@163.com; lwuyi@fynu.edu.cn

$\triangle$ Zafar Iqbal Khan

zafar.khan@uos.edu.pk; zikhan11@gmail.com

1 Department of Science and Technology, Anhui Province Key Laboratory of Environmental Hormone and Reproduction,

Fuyang Normal University, Fuyang, Anhui, China

2 Department of Botany, University of Sargodha, Lahore, Punjab, Pakistan

3 Institute of Food Science and Nutrition, University of Sargodha, Sargodha, Pakistan 